\title{
Decisões jurisprudenciais sobre a inconstitucionalidade das eleições diretas para escolha dos diretores das escolas públicas brasileiras
}

Jurisprudencial decisions on the unconstitutionality of direct elections to choose the directors of brazilian public schools

Sentencia de decisiones sobre la inconstitucionalidad de las elecciones directas para elegir a los directores de las escuelas públicas brasileñas

\author{
Paulo Sérgio de Almeida Corrêa \\ Universidade Federal do Pará (Brasil) \\ http://lattes.cnpq.br/7102416953096612 \\ http://orcid.org/0000-0002-9975-9919 \\ paulosac@ufpa.br
}

\section{Resumo}

Objetivou-se catalogar e analisar o conjunto de Jurisprudências formadas a partir das decisões oriundas do Supremo Tribunal Federal e do Superior Tribunal de Justiça, tendo por objeto a temática relacionada ao instituto das eleições diretas nas escolas públicas. Estudo bibliográfico e documental, no período de 1988-2017. Encontra-se pacificado no STF e STJ que, tanto as Constituições Estaduais quanto suas leis, decretos e resoluções, carregam consigo vícios insanáveis, os quais são incompatíveis com as previsões abrigadas na atual Constituição Federal.

Palavras-chave: Escolas públicas. Escolha de Diretores. Inconstitucionalidade. 


\begin{abstract}
The objective was to catalog and analyze the set of jurisprudences formed from the decisions coming from the Supreme Federal Court and the Superior Court of Justice, having as their object the theme related to the institute of direct elections in public schools. Bibliographic and documentary study, from 1988-2017. It is pacified in the STF and STJ that both the State Constitutions and their laws, decrees and resolutions carry with them insanely vices, which are incompatible with the predictions contained in the current Federal Constitution.
\end{abstract}

Keywords: Public schools. Choice of Directors. Unconstitutionality.

\title{
Resumen
}

El objetivo era catalogar y analizar el conjunto de jurisprudencias formadas a partir de las decisiones de la Corte Suprema Federal y la Corte Superior de Justicia, teniendo como objeto el tema relacionado con el instituto de elecciones directas en las escuelas públicas. Estudio bibliográfico y documental, en el período de 1988-2017. En el STF y el STJ se calma que tanto las Constituciones estatales como sus leyes, decretos y resoluciones llevan consigo vicios insanables, que son incompatibles con las predicciones contenidas en la Constitución Federal vigente.

Palabras clave: Escuelas públicas. Elección de directores. Inconstitucionalidad. 


\section{Introdução}

Estudo de Paro (1996), demonstrou o caráter histórico das lutas desencadeadas pelos movimentos sociais, em particular aqueles ligados ao setor de educação, em cuja pauta reivindicatória a gestão democrática e as eleições diretas nas escolas também ganharam destaque. Apesar de toda essa trajetória que perfaz os anos de 1960 à primeira metade da década de 1990, poucas realidades estaduais e municipais introduziram essa temática em suas legislações e, aquelas que lograram êxito em fazê-lo, trouxeram consigo vícios de processos eleitorais transcorridos na vida política nacional. Isto teria dificultado o fortalecimento da participação da sociedade nos processos eletivos transcorridos nas instituições escolares, uma vez que permaneciam viciadas pelas práticas clientelistas, permeadas com as condutas corporativistas, e relações populistas entre os sujeitos implicados com a vida escolar.

A respeito da relação entre gestão democrática e a qualidade da educação, a pesquisa de Maia e Manfio (2010), foi igualmente contundente em diagnosticar, mediante estudo bibliográfico, que entre os anos de 1990-2005, nas diversas localidades por onde o provimento do cargo de diretor escolar passou a se fazer mediante eleição direta, a qualidade do ensino ainda permanecia com níveis precários.

Estudo feito por Brzezinski e Mata, (2009), abordou o fenômeno das eleições para escolha de diretores das escolas estaduais, concentrando-se a análise sobre a realidade do Estado de Goiás, expondo-se os conflitos entre o Conselho Estadual de Educação e o Sindicato dos Trabalhadores da Educação. Igualmente relevante foi o trabalho de Santos e Prado (2013), no qual discutiram a relação entre gestão democrática e eleição de diretores em municípios de Alagoas. Por sua vez, a pesquisa de Silva (2000), abordou a trajetória histórica, impasses e perspectivas relacionadas à escolha de diretores das escolas no caso do Estado de Minas Gerais; enquanto Medeiros (2006), discorreu sobre a gestão democrática e escolha do diretor de escola; e Oliveira (2017), concentrou sua análise no instituto das eleições diretas para diretor de escolas na Região Metropolitana de Belém, no Estado do Pará.

Por sua vez, o trabalho de Freitas, Alexandre e Silva (2012) apontou diversas dificuldades para sedimentar a democracia nos ambientes institucionais das escolas públicas brasileiras, em que pese a realização de processos de eleição direta para escolha dos ocupantes do cargo de diretor escolar.

No âmbito do Direito Constitucional no Brasil, ampliou-se o número de pesquisas cujos autores se dedicam ao estudo do controle de constitucionalidade sob diferentes perspectivas (MENDES, 1999, 2004; COSTA, CARVALHO, FARIAS, 2016; BRUST, 2009; GARCIA JÚNIOR, 2015; KUNZLER, 2017; MUZZI FILHO, MURTA, 2016; OLIVEIRA, 2016; LOPEZ, CHEHAB, 2016; LIMAS TOMIO, ROBL FILHO, KANAYAMA, 2017).

O controle de constitucionalidade passou por evolução histórica no Brasil, conforme destacam Costa, Carvalho, Farias (2016, p. 155). Todavia, embora tenha ganhado relevância a atuação do Supremo Tribunal Federal no controle concentrado e difuso, a ampliação do poder dessa Corte não diminuiu a sobrecarga de trabalho, mas atenuou as atividades quanto ao julgamento de mérito, principalmente mediante restrições no número de acórdãos proferidos. Além disso, ressaltam que:

O processo de aumento dos efeitos do controle concentrado também ocorreu no âmbito das possibilidades hermenêuticas à disposição do STF. Ele foi acentuado com a consolidação do instituto da "interpretação conforme", que ocorreu pela primeira vez em ementas do Supremo em 1987 (STF, Rp 1417) e consolidou-se ao longo da década de 1990, quando as referências jurisprudenciais passaram a ser constantes, tendo sido inclusive reconhecido legislativamente pelo art. 
28 da Lei n. 9868/1999. Essa estratégia interpretativa conferiu ao STF a possibilidade de editar sentenças interpretativas de constitucionalidade que, como bem acentua Leo Brust (2009), corrigem ou estendem a obra do legislador sem alterar o então predominante discurso do legislador negativo. Outros marcos importantes desse processo foram a reforma do Judiciário realizada pela EC 45/2004, que instituiu as súmulas vinculantes, e a mudança jurisprudencial que, no julgamento do Mandado de Injunção (MI) 670/ES, em 2007, adotou maior ativismo no tratamento da inconstitucionalidade por omissão (COSTA, CARVALHO, FARIAS, 2016, p.158).

Garcia Júnior (2015) realizou um estudo histórico e jurídico a respeito da evolução do controle jurisdicional de constitucionalidade no ordenamento brasileiro, examinando as principais características assumidas nas diversas constituições do Brasil, com atenção especial ao modelo atual erigido a partir da Constituição Federal de 1988.

No trabalho de Kunzler (2017), focalizou-se "a origem e o fundamento teórico das diversas escolas sobre a interpretação do Direito Constitucional, e o exercício do controle de constitucionalidade em matérias tributária no Brasil", percebendo-se os efeitos das decisões proferidas pelo Supremo Tribunal Federal, com base na aplicação do chamado princípio da segurança jurídica e daquele configurado como de excepcional interesse social.

Para Muzzy Filho (2016), a atuação do Supremo Tribunal Federal no controle de constitucionalidade passou por crises históricas e revela a incapacidade dessa Corte para julgar aqueles processos a ela submetidos, por mais que tenham ocorrido reformas visando aprimorar o modelo, não houve resolução das crises, sendo, portanto, necessário reduzir as competências jurisdicionais atribuídas ao STF.

Conforme pesquisa de Oliveira (2016), o exercício do controle de constitucionalidade das leis no Brasil, é permeado pelas disputas e interesses mediante os diferentes papeis do Supremo Tribunal Federal quando do exame e julgamento das Ações Diretas de Inconstitucionalidades, constituindo-se como um órgão que delibera muito mais de forma corporativa do que em favor da implementação de direitos sociais e coletivos.

A análise de Lopes e Chehab (2016), demonstrou que, no caso brasileiro, tanto o controle de constitucionalidade quanto o controle de convencionalidade, ainda são vistos com receio em razão de prevalecer o desconhecimento de seus benefícios e o temor na utilização das normas advindas de tratados internacionais, visando a não aplicação de normas internas.

Os resultados do estudo de Limas Tomio, Robl Filho, Kanayama (2017), indicaram que, em perspectiva de uma história comparada dos casos do Brasil, Espanha, Itália, México e Portugal, o controle de constitucionalidade abstrato e concentrado produz impactos sobre os conflitos nacionais e subnacionais, uma vez que a jurisdição constitucional favorece a manutenção ou aumento dos poderes do governo central ou nacional.

Outra pesquisa relevante foi desenvolvida por Correa, Walmott Borges, Pinhão (2019), a qual apontou que as audiências públicas cumprem importante papel enquanto espaços na legitimação democrática no exercício do controle de constitucionalidade concentrado, trazendo implicações positivas sobre a construção de uma sociedade democrática. Além disso, Schmitt (2014), ressaltou que os Tribunais de Contas existentes no Brasil, também cumprem relevante papel no exercício do controle de constitucionalidade.

Verifica-se, pois, que em matéria constitucional, além do STF, e das competências atribuídas aos juízes e tribunais (CF 1988, art. 97, art. 102, III, $a$ a $c$, art. 105, II, $a$ e $b$ ), atualmente estão legitimados à propositura de Ação Direta de Inconstitucionalidade (ADI): 
Art. 102. Compete ao Supremo Tribunal Federal, precipuamente, a guarda da Constituição, cabendo-lhe:

I - processar e julgar, originariamente:

a) a ação direta de inconstitucionalidade de lei ou ato normativo federal ou estadual e a ação declaratória de constitucionalidade de lei ou ato normativo federal;

Art. 103. Podem propor a ação direta de inconstitucionalidade e a ação declaratória de constitucionalidade:

I - o Presidente da República;

II - a Mesa do Senado Federal;

III - a Mesa da Câmara dos Deputados;

IV - a Mesa de Assembleia Legislativa ou da Câmara Legislativa do Distrito Federal;

V - o Governador de Estado ou do Distrito Federal;

VI - o Procurador-Geral da República;

VII - o Conselho Federal da Ordem dos Advogados do Brasil;

VIII - partido político com representação no Congresso Nacional;

IX - confederação sindical ou entidade de classe de âmbito nacional.

$\S 1^{\circ} \mathrm{O}$ Procurador-Geral da República deverá ser previamente ouvido nas ações de inconstitucionalidade e em todos os processos de competência do Supremo Tribunal Federal.

$\S 2^{\circ}$ Declarada a inconstitucionalidade por omissão de medida para tornar efetiva norma constitucional, será dada ciência ao Poder competente para a adoção das providências necessárias e, em se tratando de órgão administrativo, para fazê-lo em trinta dias.

$\S 3^{\circ}$ Quando o Supremo Tribunal Federal apreciar a inconstitucionalidade, em tese, de norma legal ou ato normativo, citará, previamente, o Advogado-Geral da União, que defenderá o ato ou texto impugnado.

$\S 4^{\circ}$ (Revogado). (BRASIL, 1988).

O controle abstrato das normas foi convertido em alvo da nova sistemática normativa trazida pela Constituição Federal de 1988, uma vez que teria ampliado o número de legitimados inclusive com a participação de órgãos de representatividade da sociedade:

Esse fato fortalece a impressão de que, com a introdução desse sistema de controle abstrato de normas, com ampla legitimação e, particularmente, a outorga do direito de propositura a diferentes órgãos da sociedade, pretendeu-se reforçar o controle abstrato de normas no ordenamento jurídico brasileiro como peculiar instrumento de correção do sistema geral incidente (MENDES, 2004, p. 2).

Nesse contexto, instituiu-se um novo paradigma de controle de constitucionalidade no ordenamento jurídico brasileiro, a partir do qual se atribuiu ao Supremo Tribunal Federal a guarda da Constituição: 
A Constituição de 1988 conferiu ênfase, portanto, não mais ao sistema difuso ou incidente, mas ao modelo concentrado, uma vez que, praticamente, todas as controvérsias constitucionais relevantes passaram a ser submetidas ao Supremo Tribunal Federal, mediante processo de controle abstrato de normas. A ampla legitimação, a presteza e a celeridade desse modelo processual, dotado inclusive da possibilidade de se suspender imediatamente a eficácia do ato normativo questionado, mediante pedido de cautelar, constituem elemento explicativo de tal tendência (MENDES, 2004, p. 2).

Mendes (1999), esclareceu que, em relação ao controle de constitucionalidade abstrato das normas, as decisões de mérito produzidas no âmbito do Supremo Tribunal Federal, geram efeitos vinculantes sobre o Poder Judiciário e o Poder Executivo.

Uma vez tendo sido produzida, aprovada, sancionada e publicada uma lei, sua eficácia técnica não significa que esteja livre de vícios, podendo ensejar a arguição de sua inconstitucionalidade em face de um direito. O que implicará em apreciação da demanda interposta perante ao Supremo Tribunal Federal.

Diante desse contexto, pergunta-se: a realização de eleição direta nas escolas seria constitucional ou estaria contaminada por vícios, logo, padeceria de inconstitucionalidade?

$\mathrm{Na}$ construção desta investigação, fez-se o estudo bibliográfico e consulta às jurisprudências existentes no Superior Tribunal de Justiça http://www.stj.jus.br/SCON/pesquisar.jsp e no Supremo Tribunal Federal http://portal.stf.jus.br/jurisprudencia/.

Os Acórdãos e Jurisprudências analisados, evidenciaram que em diferentes unidades federadas do Brasil, as formas de preenchimento do cargo/função de diretor, ocorrem por meio da indicação política como cargo comissionado, mesmo tendo sido deflagrado processo seletivo via eleição direta, segundo lei específica, fortalecendo o poder discricionário do Chefe do Executivo na admissão ou demissão do contratado ${ }^{1}$.

De acordo com o estabelecido na Constituição da República Federativa do Brasil, promulgada no ano de 1988, a gestão democrática passou a se constituir em princípio essencial para o ensino, devendo inclusive a ocupação dos cargos resultar de concurso público

Art. 206. O ensino será ministrado com base nos seguintes princípios:

I - igualdade de condições para o acesso e permanência na escola;

II - liberdade de aprender, ensinar, pesquisar e divulgar o pensamento, a arte e o saber;

III - pluralismo de idéias e de concepções pedagógicas, e coexistência de instituições públicas e privadas de ensino;

IV - gratuidade do ensino público em estabelecimentos oficiais;

V - valorização dos profissionais da educação escolar, garantidos, na forma da lei, planos de carreira, com ingresso exclusivamente por concurso público de provas e títulos, aos das redes públicas;

VI - gestão democrática do ensino público, na forma da lei;

VII - garantia de padrão de qualidade;

\footnotetext{
${ }^{1}$ Situação diferente ocorre no Estado de São Paulo, que atualmente promove concursos públicos para ingresso no Quadro do Magistério no exercício de Diretor de Escola, segundo as normas expressas na Resolução SE 56, de 14-10-2016, que "Dispõe sobre perfil, competências e habilidades requeridos dos Diretores de Escola da rede estadual de ensino, e sobre referenciais bibliográficos e legislação, que fundamentam e orientam a organização de concursos públicos e processos seletivos, avaliativos e formativos, e dá providências correlatas".
} 
VIII - piso salarial profissional nacional para os profissionais da educação escolar pública, nos termos de lei federal.

Parágrafo único. A lei disporá sobre as categorias de trabalhadores considerados profissionais da educação básica e sobre a fixação de prazo para a elaboração ou adequação de seus planos de carreira, no âmbito da União, dos Estados, do Distrito Federal e dos Municípios (BRASIL, 1988).

Percebeu-se que o controle de constitucionalidade tem fortalecido o poder discricionário dos chefes do Poder Executivo nas diferentes unidades federadas do Brasil, uma vez que naqueles lugares em que passou a existir lei específica regulamentadora das eleições diretas nas escolas, todas elas foram julgadas inconstitucionais porque o preenchimento do cargo/função de diretor resultou de indicação política e não de expresso concurso público.

Assim, em face das decisões do STF já pronunciadas quanto ao mérito, o Superior Tribunal de Justiça vem reiterando as deliberações da Suprema Corte, ratificando os efeitos vinculantes de seus julgados.

\section{Eleições diretas nas escolas segundo o conteúdo jurisprudencial do Superior Tribunal de Justiça}

No caso do STJ, a pesquisa por Jurisprudências, mediante a palavra-chave "escolha de diretores de escolas", evidenciou que atualmente existem 15 pronunciamentos disponíveis, sendo 01 Acórdão $^{2}$ e 14 Decisões Monocráticas ${ }^{3}$. Todavia, ao processar a leitura de cada um desses documentos, constatou-se que nem todos se referem ao tema deste estudo, o que implicou na redução desse quantitativo, mantendo-se o Acórdão, mas concentrando a análise em 10 Decisões.

Notou-se que, desde o ano de 1997, o STJ tem se pronunciado sobre diversos casos envolvendo a escolha de diretores das escolas públicas por meio das eleições diretas. Houve situações em que o candidato eleito sofreu sua dispensa por ter se envolvido em manifestação de apoio à greve, porém, em diversos outros casos, a retirada do cargo foi ato discricionário praticado pelo Chefe do Poder Executivo, e isto passou a evidenciar que os diretores poderiam ter sua nomeação cassada a qualquer tempo, porque não se trata de um direito líquido e certo. A título de exemplo, vejam-se alguns casos abaixo.

Em sede do Recurso Ordinário em Mandado de Segurança RMS 3699 (1993/00285165 - 04/08/2003), cerca de 10 anos após o surgimento da demanda, o STJ decidiu pela legalidade a dispensa do diretor de escola em razão de falta grave e pelo fato de a ocupação desse cargo em comissão poder ser alvo de exoneração a qualquer tempo.

DIREITO ADMINISTRATIVO. MANDADO DE SEGURANÇA. DIRETORES DE ESCOLAS PÚBLICAS. DISPENSA. CARGO EM COMISSÃO. EXONERAÇÃO "AD NUTUM". LEGALIDADE. PRECEDENTES DO STJ. - O ato do Secretário de Estado da Educação que dispensou os Recorrentes dos cargos comissionados que ocupavam, ante o cometimento de falta grave, reveste-se de legalidade, pois o cargo de confiança tem como pressuposto essencial a possibilidade de exoneração "ad nutum". Precedentes do STJ. - Recurso conhecido, porém, desprovido.

Assim se pronunciaram no Relatório:

\footnotetext{
${ }^{2}$ Refere-se a uma decisão final ou sentença proferida por instância superior que passa a ter seus efeitos sobre os demais casos semelhantes.

${ }^{3}$ É aquela decisão proferida por um único magistrado, esteja ele vinculado a qualquer grau de jurisdição. $\mathrm{Na}$ primeira instância ela é tida como a regra a ser seguida, na segunda, torna-se a exceção.
} 
Trata-se de recurso ordinário em mandado de segurança interposto por AMAURY BARBOSA e OUTROS, assistidos pela gratuidade judiciária, em face do acórdão proferido pelo Tribunal de Justiça do Estado do Rio de Janeiro, que denegou a segurança pleiteada no writ originário. Os Impetrantes objetivaram, por intermédio de ação mandamental, a recondução nas funções de Diretor e Diretores-Adjuntos do Centro Integrado de Educação Pública Dom Pedro D'Alcântara de Bragança Primeiro Imperador do Brasil - CIEP, e, por conseguinte, a revogação do ato administrativo que, sem o devido processo administrativo, culminou por demiti-los "ad nutum". Alegaram, para tanto, que foram injustificadamente demitidos pela Secretária Estadual de Educação do Estado do Rio de Janeiro, por participarem de movimento grevista, sem que houvesse, todavia, contraditório administrativo.

Tornar-se um diretor de escola, ainda que mediante processo eleitoral resultante da aplicação de lei específica, não significa que o mesmo tenha alcançado a impossibilidade de sua retirada do caro/função, pois o ato de nomeação pode vir a ser tornado sem efeito.

O fato de poder ser dispensado a qualquer tempo do cargo/função de diretor escolar, demonstra que não se exige observância ao contraditório e à ampla defesa à parte prejudicada, visto ser dispensável a instauração de processo administrativo a fim de realizar a destituição do então beneficiário indicado.

Proveniente de Minas Gerais, teve origem o AGRAVO EM RECURSO ESPECIAL N ${ }^{\circ}$ 904.171 - MG (2016/0120742-0), julgado na instância do STJ em 17/05/2017, cuja decisão enfatizou:

No caso dos autos, verifico que o acórdão impugnado afastou a tese da acusação sob o argumento de que "a lei que determina a ocorrência de eleição para investidura em cargos de direção e vice-direção de escolas públicas fere o disposto na Constituição Federal, pois retira do chefe do executivo a prerrogativa constitucional de nomear, de forma livre, servidores em cargo de comissão" (fl. 476).

Assim, o Tribunal de origem, em atenção ao que já vem decidindo o Supremo Tribunal Federal em casos semelhantes, entendeu por rejeitar a denúncia, uma vez que "o ato do Prefeito Municipal de Sacramento de nomear servidores para ocupação de cargos de direção e vice-direção de escolas municipais não fora ilícitos" (fl. 470).

Nesse sentido, entendo não ser cabível a interposição de recurso especial com fundamento em violação de dispositivo constitucional, conforme disposto no art. 105, III, "a", da Constituição Federal, sob pena de afronta à competência reservada ao Supremo Tribunal Federal.

Percebe-se que a criação de lei no âmbito das Unidades Federadas, visando regulamentar o instituto das eleições diretas nas escolas, é tipicamente inconstitucional, pois retira a competência do Poder Executivo de nomear e destituir os ocupantes em cargos/funções comissionados, inexistindo qualquer ilicitude no ato oficial que destituir o servidor.

Outro caso é proveniente do Paraná - SC, mediante RECURSO EM MANDADO DE SEGURANÇA N 15.320 - PR (2002/0108680-0), interposto junto ao STJ e somente julgado em 06 de maio de 2015, com o seguinte conteúdo decisório: 
O cerne da controvérsia reside na legalidade dos atos de exoneração de cargos em comissão de diretores de escolas públicas do Estado do Paraná, após o julgamento pelo STF da ADI 606-1, que declarou inconstitucional a eleição de diretores nas instituições de ensino mantidas pelo Poder Público Estadual.

Com efeito, o acórdão recorrido está em harmonia com a orientação jurisprudencial desta Corte Superior, no sentido de que a exoneração de servidor ocupante de cargo em comissão prescinde de motivação, porquanto se trata ato discricionário.

Nota-se que, no Estado do Paraná, a eleição para escolha de diretores das escolas públicas, já foi julgada como inconstitucional, logo, os atos do Poder Executivo para nomear e destituir do cargo/função, não está revestido de nenhuma ilegalidade, principalmente por se tratar de um poder discricionário, ou seja, dependente da vontade do Chefe do Executivo para manter/dispensar o servidor.

No Espírito Santo, no julgamento do RECURSO EM MANDADO DE SEGURANÇA No 26.017 - ES (2008/0000785-5), ocorrido em 09 de setembro de 2013, o STJ também decidiu:

Ao contrário do que alega a impetrante, a eleição para a função de Diretor de Unidade Escolar do Sistema Estadual de Ensino, por ser cargo de natureza comissionada, não confere aos eleitos o direito de somente serem dispensados de suas funções ao término de seus mandatos, ou na hipótese de terem praticados infrações funcionais, devidamente apurada por meio de procedimento administrativo.

Uma vez nomeados os diretores dos estabelecimentos escolares, tal assunção ao cargo não lhes assegura a permanência por todo o tempo de exercício previsto (2, 3 ou 4 anos), visto que, por ter natureza de cargo comissionado, o Poder Executivo goza da prerrogativa de romper o vínculo funcional a qualquer momento, inclusive sem a necessidade de gerar processo administrativo.

Julgado no STJ em 02 de fevereiro de 2007, o RECURSO EM MANDADO DE SEGURANÇA N 22.882 - RJ (2006/0218857-2), decidiu sobre matéria de eleição para diretor, transcorrida no Município de Nova Iguaçu, no Estado do Rio de Janeiro:

Consoante se verifica nos autos, insurge-se o recorrente contra ato do Sr. Prefeito do Município de Nova Iguaçu-RJ, consistente na nomeação e posse de candidata da Chapa 1 ao cargo Diretor Escolar, em razão de supostas nulidades no processo eleitoral.

Em que pesem os argumentos expendidos pelo recorrente, suas razões em nenhum momento conseguiram abalar os fundamentos esposados pelo v. acórdão a quo, que concluiu pela inexistência de direito líquido e certo a ser tutelado.

$\mathrm{O}$ voto condutor do decisum, assim consignou: "A pretensão do Impetrante, ao invocar legislação municipal para amparar o alegado direito líquido e certo, esbarra na regra constitucional do artigo 37, II, da Constituição Federal.

Como bem assinado no douto parecer ministerial, com citação doutrinária abalizada, o pleito eleitoral não retira o poder de exoneração e nomeação de cargo de confiança pelo Prefeito. 
Outrossim, no caso concreto, o pleito foi realizado e com base no seu resultado, a Autoridade Impetrada, no exercício de suas prerrogativas, fez a nomeação do vencedor.

Candidato que por ventura tenha sido investido ao cargo após realização do pleito eleitoral para escolha de diretores, não se torna detentor de direito líquido e certo em face do Poder Executivo, uma vez que a sua nomeação está vinculada a um cargo de confiança e, por isso, pode ser desfeita a qualquer momento pela autoridade constituída.

A apreciação das decisões jurisprudenciais ocorridas na esfera do STJ, dão provas de que as legislações que originaram e regulamentaram as eleições diretas nas escolas no âmbito estadual e municipal, são reconhecidamente inconstitucionais, portanto, inócuas no mundo jurídico.

Além disso, a ocupação do cargo/função de diretor das escolas públicas, não gera direito líquido e certo ao favorecido por esse ato oficial, isto porque se trata de lugar comissionado, para o qual o Poder Executivo detém o poder de admitir e/ou exonerar o indicado, inclusive prescindindo de qualquer processo administrativo.

\section{Os acórdãos no âmbito das decisões jurisprudenciais no Supremo Tribunal Federal}

Consultando a base de dados do Supremo Tribunal Federal - STF no sítio http://www.stf.jus.br/portal/jurisprudencia/, por meio da busca na Pesquisa livre com a expressão de busca "eleição de diretor de escola", verificou-se a existência 12 Acórdãos nos quais houve decisões sobre o assunto.

No dia 12/08/2009, o Tribunal Pleno realizou o julgamento da ADI 2997/RJ RIO DE JANEIRO AÇÃO DIRETA DE INCONSTITUCIONALIDADE, na qual decidiu que:

EMENTA: INCONSTITUCIONALIDADE. Ação direta. Art. 308, inc. XII, da Constituição do Estado do Rio de Janeiro. Normas regulamentares. Educação. Estabelecimentos de ensino público. Cargos de direção. Escolha dos dirigentes mediante eleições diretas, com participação da comunidade escolar. Inadmissibilidade. Cargos em comissão. Nomeações de competência exclusiva do Chefe do Poder Executivo. Ofensa aos arts. $2^{\circ}, 37$, II, 61, $\S 1^{\circ}$, II, "c", e 84, II e XXV, da CF. Alcance da gestão democrática prevista no art. 206, VI, da CF. Ação julgada procedente. Precedentes. Voto vencido. É inconstitucional toda norma que preveja eleições diretas para direção de instituições de ensino mantidas pelo Poder Público, com a participação da comunidade escolar.

Nos estabelecimentos públicos de ensino, em face de sua inconstitucionalidade, tornouse inadmissível a realização da escolha de diretores das unidades escolares por meio de eleições diretas, pois as nomeações ou desligamento de servidores dos cargos em comissões, compete exclusivamente aos Chefes dos Poderes Executivos.

Tratando-se da ADI 2997 MC/RJ - RIO DE JANEIRO MEDIDA CAUTELAR NA AÇÃO DIRETA DE INCONSTITUCIONALIDADE, no julgamento ocorrido no dia 29/10/2003, o Tribunal Pleno decidiu pela inconstitucionalidade do conjunto de normas expressas em Constituição e leis estaduais, nas quais haja previsão de ocorrência das eleições diretas nas escolas mantidas pelo poder público: 
EMENTA: INCONSTITUCIONALIDADE. Ação Direta. Constituição e leis estaduais. Projeto de iniciativa de deputado, quanto a uma das leis. Educação. Direção de instituições de ensino mantidas pelo Poder Público. Normas que prevêem eleições diretas, com participação da comunidade escolar. Ofensa aparente aos arts. $2^{\circ}, 37$, II, 61, § $1^{\circ}$, II, "c", e 84, II e XXV, da CF. Risco manifesto de dano à administração pública. Medida cautelar concedida. Precedentes. Deve ser concedida, em ação direta de inconstitucionalidade, medida cautelar para suspensão da vigência de normas de Constituição e de leis estaduais que prevêem eleições diretas, com participação da comunidade escolar, para os cargos de direção das instituições de ensino mantidas pelo Poder Público.

Além de se constituir uma ofensa à Constituição Federal, a justiça deve conceder medida cautelar visando suspender a vigência de normas infraconstitucionais referentes ao instituto das eleições diretas nas escolas públicas, com ampla participação da comunidade escolar.

No Estado do Rio Grande do Sul, o Tribunal Pleno julgou no dia 03 de março de 1999 a ADI 578/RS - RIO GRANDE DO SUL AÇÃO DIRETA DE INCONSTITUCIONALIDADE, a qual também reconhecia a inconstitucionalidade das leis estaduais regulamentadoras das eleições diretas para escolha dos diretores das escolas:

EMENTA: AÇÃO DIRETA DE INCONSTITUCIONALIDADE. CONSTITUIÇÃO DO ESTADO DO RIO GRANDE DO SUL, ARTIGO 213, § $1^{\circ}$. LEIS GAÚCHAS NS 9.233/91 E 9.263/91. ELEIÇÃO PARA PROVIMENTO DE CARGOS DE DIRETORES DE UNIDADE DE ENSINO. INCONSTITUCIONALIDADE. 1. É competência privativa do Chefe do Poder Executivo o provimento de cargos em comissão de diretor de escola pública. 2. Constituição do Estado do Rio Grande do Sul, artigo 213, § $1^{\circ}$, e Leis estaduais ns 9.233 e 9.263 , de 1991. Eleição para o preenchimento de cargos de diretores de unidade de ensino público. Inconstitucionalidade. Ação Direta de Inconstitucionalidade procedente.

Veja-se que mesmo no caso de leis que tenham surgido após a Constituição da República Federativa do Brasil de 1988 e antes da Lei de Diretrizes e Bases da Educação Nacional LDBEN, de 1996, o julgamento da ADI demonstrou ser inconstitucional toda e qualquer lei criada pelas Unidades Federadas com intuito de realizar a escolha de diretores das escolas mediante processos eleitorais que envolvam a comunidade escolar.

Em situação jurídica referente ao Estado de Minas Gerais, no dia 05 de fevereiro do ano de 1997, o Tribunal Pleno do STF realizou o julgamento da ADI 640/MG - MINAS GERAIS AÇÃO DIRETA DE INCONSTITUCIONALIDADE, decidindo-se pela inconstitucionalidade do provimento de cargos de diretor de escolas estaduais, por meio de eleições diretas:

EMENTA: AÇÃO DIRETA DE INCONSTITUCIONALIDADE. PROVIMENTO DOS CARGOS DE DIREÇÃO DE UNIDADES ESTADUAIS DE ENSINO POR ELEIÇÃO: ART. 196, VIII, DA CONSTITUIÇÃO ESTADUAL, LEI $\mathrm{N}^{\circ}$ 10.486, DE 24.07.91, E DECRETO $\mathrm{N}^{\circ}$ 32.855, DE 27.08.91, TODOS DO ESTADO DE MINAS GERAIS. INCONSTITUCIONALIDADE: ART. 37, II, IN FINE, DA CONSTITUIÇÃO FEDERAL. 1. Cabe ao Poder Executivo fazer as nomeações para os cargos em comissão de diretor de escola 
pública (CF, art. 37, II, in fine). 2. É inconstitucional a norma legal que subtrai esta prerrogativa do Executivo, ao determinar a realização de processo eleitoral para o preenchimento destes cargos. 3. Ação direta julgada procedente para declarar a inconstitucionalidade do art. 196, VIII, da Constituição Estadual, da Lei ${ }^{\circ} 10.486 / 91$ e do Decreto ${ }^{\circ}$ 32.855/91, todos do Estado de Minas Gerais.

Tal decisão esclarece que tanto as Constituições estaduais, as leis estaduais e seus Decretos regulamentadores, são inconstitucionais quando fixam normas envolvendo a escolha dos diretores das escolas, visto que ameaçam retirar do Poder Executivo a prerrogativa para determinar a indicação ou demissão de servidor para ocupação desse cargo/função nas instituições públicas de ensino.

Com relação ao Estado de Santa Catarina, o Tribunal Pleno do STF, julgou no dia 03 de fevereiro do ano de 1997, a ADI 573/SC - SANTA CATARINA AÇÃO DIRETA DE INCONSTITUCIONALIDADE, pronunciando-se pela inconstitucionalidade da Constituição Estadual e de leis específicas concernentes ao processo de escolha dos diretores das escolas estaduais:

EMENTA: - Ação direta de inconstitucionalidade. 2. Lei $\mathrm{n}^{\circ}$ 8040, de 26.7.1990, do Estado de Santa Catarina, que dispõe sobre as funções de direção de escolas públicas, forma de escolha dos diretores, dando outras providências. 3. Escolha, por eleição da comunidade escolar, dos diretores. 4. Alegação de ofensa aos arts. 61, § 1º II, letra "c", e 37, II, da Constituição Federal, porque a lei foi de iniciativa parlamentar e concerne ao provimento de cargos em comissão. 5. Cautelar deferida. 6. Orientação do STF no sentido de não abonar, à luz dos preceitos constitucionais em vigor, a eletividade dos diretores das escolas públicas. Sendo os diretores de estabelecimentos públicos, que se integram no organismo do Poder Executivo, titulares de cargos ou funções em comissão, não seria admissível a intitulação nesses cargos, com mandatos que lhes assegurariam professores, servidores e alunos, sem a manifestação do Chefe do Poder Executivo, que ficaria vinculado a essa escolha para prover cargos de confiança, com vistas a gerir cargos do ruolo administrativo, integrantes da estrutura educacional. 7. Precedentes nas ADINs ns 244-9-RJ, 387-9-RO, 578-2-RJ, 640-1-MG, 606-1-PR, 123- 0-SC e 490-5. 8. Ação direta de inconstitucionalidade julgada procedente, declarando-se a inconstitucionalidade da Lei $\mathrm{n}^{\mathbf{o}}$ 8040, de 26.7.1990, do Estado de Santa Catarina.

O preenchimento da função de diretor em cargo de comissão, não deve estar prevista em lei de iniciativa do Poder Legislativo estadual porque contraria norma constitucional federal. Além disso, os mandatos derivados de processos eletivos dos quais participam professores, servidores e alunos, não podem ser validados, uma vez que suprime prerrogativa atribuída ao Chefe do Poder Executivo.

Proveniente dessa mesma Unidade Federada de Santa Catarina, o Tribunal Pleno do STF julgou no dia 03 de fevereiro de 1997, a ADI 123/SC - SANTA CATARINA. AÇÃO DIRETA DE INCONSTITUCIONALIDADE, cuja decisão demonstrava ser inconstitucional dispositivo normativo presente em texto da Constituição Estadual: 
EMENTA: CONSTITUCIONAL. ENSINO PÚBLICO. DIRETORES DE ESCOLAS PÚBLICAS: ELEIÇÃO: INCONSTITUCIONALIDADE. Constituição do Estado de Santa Catarina, inciso VI do art. 162. I. - É inconstitucional o dispositivo da Constituição de Santa Catarina que estabelece o sistema eletivo, mediante voto direto e secreto, para escolha dos dirigentes dos estabelecimentos de ensino. É que os cargos públicos ou são providos mediante concurso público, ou, tratando-se de cargo em comissão, mediante livre nomeação e exoneração do Chefe do Poder Executivo, se os cargos estão na órbita deste (C.F., art. 37, II, art. 84, XXV). II. Ação direta de inconstitucionalidade julgada procedente.

Sendo o preenchimento dos cargos públicos realizados mediante concurso público, ou, no caso de cargo/função comissionada, por meio de nomeação feita pelo Chefe do Executivo, logo, incorre em inconstitucionalidade toda Constituição ou lei estadual da qual conste expressamente norma regulamentadora do processo de escolha de diretores das escolas públicas, pelo mecanismo do voto direto e secreto.

No dia 22 de novembro de 1991, o Tribunal Pleno do STF já havia analisado a ADI 640 MC/MG - MINAS GERAIS MEDIDA CAUTELAR NA AÇÃO DIRETA DE INCONSTITUCIONALIDADE, decidiu pela concessão de medida cautelar para suspender os efeitos de normas que preveem a escolha de diretores das escolas públicas por processo eletivo:

\begin{abstract}
ESCOLAS - DIRETORES - PROCESSO DE ESCOLHA - AÇÃO DIRETA DE INCONSTITUCIONALIDADE - CAUTELAR. Concorrem os pressupostos indispensáveis a concessão da cautelar quando os atos normativos impugnados preveem a escolha dos diretores das escolas públicas mediante processo seletivo peculiar e para o cumprimento de mandato. Ao primeiro exame, a hipótese envolve cargos a serem preenchidos a livre discrição, sendo improprio o afastamento, por norma legal, da atuação do Executivo.
\end{abstract}

Qualquer norma fixada sob a forma de Decreto, lei específica ou no texto de Constituições estaduais, não tem o poder para impedir ou mesmo suprimir a atuação do Chefe do Poder Executivo enquanto ente que reúne as competências para nomear e destituir os servidores para os cargos/funções de diretor de escolas públicas.

O Tribunal Pleno do STF, em julgamento datado de 14 de setembro de 1988, ou seja, antes da vigência da Constituição da República Federativa do Brasil, de 05 de outubro de1988, decidiu em Representação Rp 1473/SC - SANTA CATARINA REPRESENTAÇÃO, mostrou ser incompatível a nomeação de diretor de escola pública com sua escolha feita mediante processos eleitorais envolvendo professores, pais e alunos:

REPRESENTAÇÃO DE INCONSTITUCIONALIDADE. Nomeação para cargo em comissão de diretor de escola pública, mediante eleição pelos professores, alunos e pais de alunos. Sendo o cargo em comissão conformado a confiança do poder nomeante, não se conciliam a livre nomeação com a escolha por eleição. A constituição limita o provimento dos cargos públicos as formas previstas no artigo 97, parágrafos 1. e 2., não deixando margem a que seja criado processo eletivo para os cargos em comissão. Não tendo as escolas públicas de primeiro grau a autonomia administrativa e financeira conferida a universidade, não há que cogitar da 
investidura em seus cargos de direção por eleição. Representação julgada procedente e declarada inconstitucional o artigo 1. Da lei 6.709, de 12 de setembro de 1985, do Estado de Santa Catarina ${ }^{4}$.

Os cargos em comissão, submetem-se à indicação do Poder Executivo, portanto, mesmo que tenha sido instituído e regulamentado mediante lei ou Decreto, em face da Constituição, o processo eleitoral que determina a escolha dos diretores de escolas públicas pelo voto direto, secreto e universal, não encontra amparo constitucional, principalmente porque esses espaços educativos não são detentores de autonomia administrativa nem financeira.

Percebe-se que os julgamentos realizados no âmbito do STF, trouxeram importantes reflexões a respeito do instituto das eleições diretas para escolha dos diretores de escolas públicas. Demonstrou que a Constituição deve prevalecer em face das Constituições estaduais, leis e decretos regulamentadores dos processos eletivos para provimento de cargo/função de diretor.

Por outro lado, restou evidente que o Chefe do Poder Executivo (seja ele estadual, municipal, ou mesmo no Distrito Federal) goza da prerrogativa sobre o poder de nomeação ou destituição do cargo do diretor das escolas públicas. Por isso, não podem os processos eletivos suprimir essa discricionariedade amparada constitucionalmente, mesmo que deles participem professores, servidores, alunos, pais ou seus representantes legais.

É importante destacar que desde setembro do ano de 1988, o Tribunal Pleno do STF já decidiu ser inconstitucional a previsão de processos eleitorais para escolha de diretores das escolas públicas, sejam eles inscritos em Constituições Estaduais, leis, decretos ou resoluções. Não podem tais normas aí previstas, solapar com a competência do Chefe do Poder Executivo para nomear ou destituir o servidor do cargo/função dessas instituições educativas.

\section{Conclusões}

Se, de um lado, tem-se como vantajoso o esmero das lutas sociais no intuito de assegurar a legalidade dos processos de escolhas de diretores das unidades escolares, de outro, no contexto dos anos de 1988 aos dias atuais, a regulamentação do instituto das eleições diretas nas escolas já se revestia de matéria extemporânea e marcada pelo anacronismo dessa pauta reivindicatória, visto que, no mês de setembro do ano de 1988, quando ainda vigia a outorgada Constituição do Brasil de $1967^{5}$, o STF, pela primeira vez, com fundamento no art. $95, \S 2^{\circ}$, decidiu sobre a inconstitucionalidade da escolha de diretores mediante eleição direta com participação da comunidade escolar, pois competia ao Chefe do Poder Executivo a liberdade para nomear ou exonerar a qualquer tempo.

A pesar da existência desse julgamento na órbita do STF e da produção de seus efeitos no ordenamento jurídico brasileiro, vários Estados pareciam seguir na contramão da história e fizeram constar em suas normas (expressas em Constituição Estadual, Lei, Decreto, Resolução) a realização do pleito eleitoral para escolher o ocupante do cargo de diretor, atribuindo-lhe forma jurídica mediante lei expressa.

Todavia, o mesmo Estado que reconhecia e validava o processo eleitoral, igualmente se converteu em autor de diversas Ações Diretas de Inconstitucionalidade perante o STF, bem como de Recursos em face do STJ, alegando a inaplicabilidade de lei por ser ela terminantemente inconstitucional.

\footnotetext{
${ }^{4}$ Por meio dessa lei, o Governo do Estado de Santa Catarina "Institui eleições e estabelece normas para a escolha de diretores das escolas públicas estaduais e dá outras providências". Disponível em http://www.leisestaduais.com.br/sc. Acesso em 05 maio de 2018.

${ }^{5}$ Em pleno recesso do Congresso Nacional, que desde 13 de dezembro de 1968 estava impedido de funcionar, tal Constituição sofreu Emenda Constitucional n ${ }^{\circ} 1$, de 17 de outubro de 1969, passando a matéria a ser regulamentada na Seção VIII Dos Funcionários Públicos, no art. 97, $\S \S 1^{\circ}$ e $2^{\circ}$.
} 
Diante da preponderância da indicação política enquanto mecanismo para guarnecer o cargo/função de diretor das escolas públicas, os resultados dos processos eleitorais tanto podem ser alvo de disputas judiciais, quanto de contendas entre os sindicatos e o Estado, ou, ainda, entre o candidato eleito pela comunidade escolar, mas que tenha sido preterido pelo Chefe do Executivo, no momento de concretizar a nomeação. Em todas essas hipóteses, impera a discricionariedade do poder estatal.

Assim, encontra-se pacificado na instância do STF e do STJ que, no caso do processo eleitoral para escolha de diretores das escolas públicas, nas Unidades Federadas, tanto as Constituições Estaduais quanto suas leis, decretos e resoluções, por mais que sejam revestidos de legalidade em relação ao processo legislativo adotado, todas essas regulamentações carregam consigo vícios insanáveis, os quais são incompatíveis com as previsões abrigadas na atual Constituição Federal.

Por essa razão, o controle de constitucionalidade exercido pelo STF no caso das eleições diretas para escolha de diretor, evidencia a necessidade de que sejam cumpridos os princípios constitucionais da valorização dos profissionais da educação, especialmente com a realização de concurso público para ocupação desse cargo/função, assim como preservando o princípio da gestão democrática na forma como se implementa a gestão das unidades de ensino.

\section{Referências}

BRASIL. Constituição da República Federativa do Brasil. 1988. Dispopnível em: http://www.planalto.gov.br/ccivil_03/constituicao/constituicao.htm. Acesso em 31 mai, 2020.

BRASIL, Instituto Brasileiro de Geografia e Estatística. $74 \%$ das cidades usam só indicação política para nomear diretor de escola. Nomeação por livre escolha do poder público é comum na rede municipal. Governo federal quer priorizar outras formas de seleção para o cargo. Disponível em: http://g1.globo.com/educacao/noticia/2015/08/74-das-cidades-usam-soindicacao-politica-para-nomear-diretor-de-escola.html. Acesso em: 21 nov. 2017.

BRASIL, Supremo Tribunal Federal - STF. Jurisprudências.

BRASIL, Superior Tribunal de Justiça - STJ. Jurisprudências.

BRUST, Leo. A interpretação conforme a constituição e as sentenças manipulativas. Rev. direito GV, São Paulo, v.5, n.2, p.507-526, Dec. 2009. Disponível em: http://www.scielo.br/scielo.php?script=sci_arttext\&pid=S1808-24322009000200014\&lng=en \&nrm=iso. Acesso em: 02 mar. 2020. https://doi.org/10.1590/S1808-24322009000200014

BRZEZINSKI, Iria; MATA, Orita de S. Medrado da Mata. Eleições de diretores para as escolas estaduais de Goiás: CEE/GO e SINTEGO inimigos ou aliados? XXIV Simpósio Brasileiro de Política e Administração da Educação III Congresso Interamericano de Política e Administração da Educação. Direitos Humanos e Cidadania: desafios para as políticas públicas e a gestão democrática da educação. Universidade Federal do Espírito Santo. Centro de Educação. Programa de Pós-Graduação (PPGE), nos dias 12, 13 e 14 de agosto de 2009. Disponível em http://www.anpae.org.br/congressos_antigos/simposio2009/143b.pdf. Acesso em: 23 nov. 2017.

CORREA, Andrey Lucas Macedo; WALMOTT BORGES, Alexandre; PINHÃO, Karina Guimarães. A democracia nas audiências públicas em controle de constitucionalidade concentrado no Brasil. Revista de Direito Brasileira, [S.1.], v. 22, n. 9, p. 29-49, jun. 2019. ISSN 2358-1352. Disponível em: https://www.indexlaw.org/index.php/rdb/article/view/4557. Acesso em: 04 mar. 2020. http://dx.doi.org/10.26668/IndexLawJournals/23581352/2019.v22i9.4557 
COSTA, Alexandre Araújo; CARVALHO, Alexandre Douglas Zaidan de; FARIAS, Felipe Justino de. Controle de constitucionalidade no Brasil: eficácia das políticas de concentração e seletividade. Rev. direito GV, São Paulo, v.12, n.1, p.155-187, Apr. 2016. Disponível em: http://www.scielo.br/scielo.php?script=sci_arttext\&pid=S1808-24322016000100155\&lng=en $\&$ nrm =iso. Acesso em: 02 mar. 2020. https://doi.org/10.1590/2317-6172201607.

ESTADO DO RIO GRANDE DO SUL. ASSEMBLÉIA LEGISLATIVA. Gabinete de Consultoria Legislativa. Lei $n^{\circ} 11.695$, de 10 de dezembro de 2001. (publicada no DOE $\mathrm{n}^{\circ} 235$, de 11 de dezembro de 2001). Altera a Lei no 10.576, de 14 de novembro de 1995, que dispõe sobre a Gestão Democrática do Ensino Público e dá outras providências. Disponível em http://www.al.rs.gov.br/filerepository/repLegis/arquivos/11.695.pdf. Acesso em 23.01.2018.

FREITAS, Priscila Alves de; ALEXANDRE, Francisca Romelha; SILVA, Ciclene Ales da. Eleições Diretas para Diretores Escolares: o caminhar da democracia no interior da escola pública brasileira. In: IV Fórum Internacional de Pedagogia, 2012, Parnaíba- Piauí. A pesquisa na graduação: emancipação humana, práxis docente, trabalho e educação, 2012.

GARCIA JÚNIOR, Antonio Luiz. Evolução Histórica do Controle de Constitucionalidade no Brasil. Revista Controle: Doutrinas e artigos, 2015, Vol.13(2), pp.278-299. https://doi.org/10.32586/rcda.v13i2.15

GOVERNO DO ESTADO DO CEARÁ. Lei $n^{\circ}$ 13.513, de 19.07.04 (DO. 27.07.04). Dispõe sobre o processo de escolha e indicação para o cargo de provimento em comissão, de Diretor junto às Escolas da Rede Pública Estadual de Ensino, e dá outras providências. Disponível em https://www.al.ce.gov.br/legislativo/tramitando/lei/13513.htm. Acesso em 20.04.2018.

GOVERNO DO ESTADO DO CEARÁ. CONSELHO DE EDUCAÇÃO DO CEARÁ. Resolução $n^{\circ}$ 414/2006. Dispõe sobre o exercício do cargo de direção de estabelecimento de ensino da educação básica. Disponível em: http://www.cee.ce.gov.br/phocadownload/ resolucoes/RES-0414-2006.pdf. Acesso em: 23 jan. 2018.

GOVERNO DO ESTADO DO CEARÁ. Resolução $n^{\circ}$ 427/2008. Altera dispositivos da Resolução CEC no 414/2006, que dispõe sobre o exercício do cargo de direção de estabelecimento de ensino da educação básica. Disponível em: http://www.cee.ce.gov.br/phocadownload/resolucoes/RESOLUCaO\%20No\%20427-2008.pdf. Acesso em 23 jan. 2018.

GOVERNO DO ESTADO DE GOIÁS. Lei $n^{\circ} 13.564$, de 08 de dezembro de 1999. Vide Lei no 14.340, de 03-12-2002. Vide Decreto $n^{\circ}$ 6.647, de 31-07-2007. Estabelece critérios para o processo de eleição de diretores dos estabelecimentos de ensino da rede pública estadual. http://www.gabinetecivil.go.gov.br/leis_ordinarias/1999/lei_13564.htm. Acesso em 11 jan. 2018.

GOVERNO DO ESTADO DE MINAS GERAIS. SECRETARIA DE ESTADO DE EDUCAÇÃO. Resolução SEE $n^{\circ} 2.795$, de 28 de setembro de 2015. Estabelece normas para escolha de servidor ao cargo de diretor e à função de vice-diretor de escola estadual de Minas Gerais e trata de outros dispositivos correlatos. Disponível em: http://www.sindutemg.org.br/ novosite/files/RESOLUCAOSEE-N-2795-DE-28-DE-SETEMBRO-DE-2015.pdf. Acesso em: 23 jan. 2018.

GOVERNO DO ESTADO DO PARÁ. Assembleia Legislativa do Pará. L e i $n^{o} 7.855$, de 12 de maio de 2014. Institui e disciplina o processo de eleição direta para Diretor e Vice-Diretor de unidade escolar da rede estadual de ensino. Disponível em: http://bancodeleis.alepa.pa.gov.br/. Acesso em 23.01.2018. 
KUNZLER, Ivo Jose. O exercício do controle de constitucionalidade no Brasil. Os princípios da segurança jurídica, da confiança e a possibilidade de mutabilidade das decisões judiciais em matéria tributária bem como, de modulação e atribuição de efeitos prospectivos às decisões judiciais do STF. Temas Socio-Jurídicos, v.36, n.73, p.153-175, 23 jul. 2017. https://doi.org/10.29375/01208578.2859

LIMAS TOMIO, Fabricio Ricardo de; ROBL FILHO, Ilton Norberto; KANAYAMA, Rodrigo Luis. Controle de constitucionalidade abstrato e concentrado no Brasil, Espanha, Itália, México e Portugal. Cuestiones Constitucionales Revista Mexicana de Derecho Constitucional, [S.1.], fev. 2017. Disponível em: https://revistas.juridicas.unam.mx/index.php/cuestionesconstitucionales/article/view/10867. Acesso em: 04 mar. 2020. http://dx.doi.org/10.22201/iij.24484881e.2017.36.10867

LOPES, Ana Maria D'Ávila; CHEHAB, Isabella Maria Campos Vasconcelos. Bloco de constitucionalidade e controle de convencionalidade: reforçando a proteção dos direitos humanos no Brasil. Revista Brasileira de Direito, 2016, Vol.12(2), pp.82-94. https://doi.org/10.18256/2238-0604/revistadedireito.v12n2p82-94

MAIA, Graziela Zambão Abdian; MANFIO, Aline. O provimento do cargo de gestor escolar e a qualidade de ensino: análise de publicações nacionais (1990-2005). RBPAE - v.26, n.3, p. 477-494, set./dez. 2010.

MEDEIROS,_Isabel Letícia Pedroso de. Gestão democrática e escolha do diretor de escola. In: Maria Beatriz Luce e Isabel Letícia Pedroso de Medeiros. (Org.). Gestão Escolar democrática: concepções e vivências. Porto Alegre: Editora da UFRGS, 2006.

MENDES, Gilmar Ferreira. O efeito vinculante das decisões do Supremo Tribunal Federal no processo de controle abstrato de normas. Presidência da República. Subchefia para Assuntos Jurídicos. Revista Jurídica Virtual, 10, Brasília, v. 1, n. 4, ago. 1999.

MENDES, Gilmar Ferreira. O controle incidental de normas no direito brasileiro. https://www.portaldeperiodicos.idp.edu.br/cadernovirtual/issue/view/11. Caderno Virtual. v. 2, n. 08 (2004) abril/junho.

MUZZY FILHO, Carlos Victor; MURTA, Antonio Carlos Diniz. O controle de constitucionalidade no Brasil: dilemas históricos do Supremo Tribunal Federal e as reformas do século XXI. Conpedi Law Review, Jan 15, 2016, Vol.2(2), p.315(20).

OLIVEIRA, Fabiana Luci. Agenda suprema: interesses em disputa no controle de constitucionalidade das leis no Brasil. Tempo Social, 01 April 2016, Vol.28(1), pp.105-133. https://doi.org/10.11606/0103-2070.ts.2016.106021

OLIVEIRA, Patrícia Soraya Cascaes Brito de. O Instituto das eleições diretas para diretor de escolas municipais da Região Metropolitana de Belém. 2017. 249 f. Dissertação (Mestrado) - Universidade Federal do Pará, Instituto de Ciências da Educação, Belém, 2017. Programa de Pós-Graduação em Educação. http://repositorio.ufpa.br/jspui/handle/2011/8716. Acesso em 22 nov. 2017.

PARO, Vitor Henrique. Eleição de Diretores de Escolas Públicas: avanços e limites da prática. Revista Brasileira de Estudos Pedagógicos, Brasília, v.77, n.186, p.376-395, maio/ago. 1996. https://doi.org/10.24109/2176-6681.rbep.77i186.1084 
SANTOS, Javan Araújo dos; PRADO, Edna Cristina do. Gestão democrática \& eleição de diretores escolares nos municípios alagoanos. In: $26^{\circ}$ Simpósio Brasileiro de Política e Administração da Educação - ANPAE, 2013, Recife/PE. Comunicações Orais G-J, 2013. v. 14.

SCHMITT, Rosane Heineck. Tribunais de Contas no Brasil e Controle de Constitucionalidade. Cadernos do Programa de Pós-Graduação em Direito PPGDir./UFRGS, Porto Alegre, n.6, nov.2014. Disponível em: https://seer.ufrgs.br/ppgdir/article/view/51623/31929. Acesso em: 04 mar. 2020. https://doi.org/10.22456/2317-8558.51623

SILVA, Marcelo Soares Pereira da. Escolha de dirigentes escolares em Minas Gerais: trajetória histórica, impasses e perspectivas. In: $23^{\text {a }}$ Reunião Anual da ANPEd, 2000, Caxambu. Anais da 23ª Reunião Anual da ANPEd, 2000. v. 1. p. 191-192. 